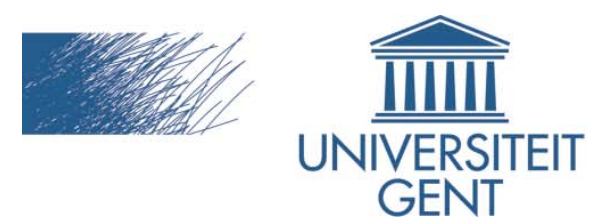

biblio.ugent.be

The UGent Institutional Repository is the electronic archiving and dissemination platform for all UGent research publications. Ghent University has implemented a mandate stipulating that all academic publications of UGent researchers should be deposited and archived in this repository. Except for items where current copyright restrictions apply, these papers are available in Open Access.

This item is the archived peer-reviewed author-version of:

Importance of health and environment as quality traits in the buying decision of organic products

Mondelaers, K., Verbeke, W., Van Huylenbroeck, G.

In: British Food Journal, 111 (10), 1120-1139, 2009.

To refer to or to cite this work, please use the citation to the published version:

Mondelaers, K, Verbeke, W, Van Huylenbroeck, G. (2009). Importance of health and environment as quality traits in the buying decision of organic products. British Food Journal 111 (10), 1120-1139. 10.1108/00070700910992952 


\title{
Importance of health and environment as quality traits in the buying decision of organic products
}

\author{
Published as... \\ Mondelaers, K, Verbeke, W, Van Huylenbroeck, G, "Importance of health and environment \\ as quality traits in the buying decision of organic products"; \\ British Food Journal; Volume: 111 (10); pp. 1120-1139 \\ http://www.emeraldinsight.com/10.1108/00070700910992952
}

\section{Category: Research Paper}

\section{Author keywords: consumer; choice preference; organic; quality; health; environment}

\section{Purpose}

This paper explores consumer preference for fresh vegetables labelled as organic in combination with health and environment related quality traits. The study decomposes organic farming into its main quality aspects and measures consumers' preference structure for organic in general and for specific organic quality traits in particular.

\section{Design / Methodology / Approach}

By means of stated choice preference modelling, the following hypotheses are tested: consumers prefer health over environment related quality traits; the organic label plays a significant role in consumers' choice for organic products; organic farming is perceived as healthier and more environmentally friendly than conventional farming; purchase intention is mainly driven by health related quality traits; both health and environmental concerns influence purchase frequency, though to a different extent. The choice experiment was completed by 527 participants, with four repetitions per participant.

\section{Findings}

The health related traits score better than environmental traits in shaping consumer preference for organic vegetables. Consumers prefer organic products over B-branded products, but not over A-branded products, which suggests that consumers classify organic products among other quality niche products. However, they attribute a better score to the health and environment related quality traits of organic products, indicating a difference in quality cues between organic products and quality products in general. Price becomes less important, whereas presence of an organic label becomes more important with increasing buying intensity of organic vegetables. Undesirable traits, such as pesticide residue levels trigger a stronger response than desirable traits, such as environmental or health benefits.

\section{Original value}

The measurement of the role of health and environment quality traits in consumers' decision to buy organic or not is of relevance given the current debate on the factual differences between organic and conventional vegetables. Furthermore, the use of the stated choice preference to test the before mentioned hypotheses is original and relevant. 


\section{Importance of health and environment as quality traits in the buying decision of organic products}

\section{Introduction}

Consumer food choice is the result of the quality expectations before and quality experience after the purchase. Based on information economics theory, a useful classification of quality dimensions for food, is the division into search, experience, and credence dimensions. Search attributes, such as colour, price and size, are considered before the actual purchase of the product and experience attributes are those which consumers perceive after the purchase and use of the product. While search and experience characteristics can be verified before or during consumption, credence attributes such as environmental impact or animal welfare are not revealed even after consuming the product (Marette et al., 1999). Credence attributes mainly focus on the quality of the production process, and less on the intrinsic characteristics of the product itself. Therefore, quality-of-life issues, such as food ethics, environment and health cannot be verified upon purchase or consumption. In recent years however, these attributes have become more important as components of consumer value (Verbeke et al., 2008). Grunert (2002) mentions quality labels as a possible solution to inform consumers about credence characteristics of food products. A typical process-related quality aspect, and consequently a credence attribute, is organic agriculture (Grunert et al., 2000).

In recent years we can notice an increasing demand for organic produce (Willer and Youssefi, 2007). The reason behind this growing interest is that organic products are perceived as less damaging to the environment and healthier than conventionally grown food products by a growing number of consumers (Chen et al., 2007). Magnusson et al. (2003) also identify concerns for health and for the environment as the two most commonly stated motives for purchasing organic foods with personal health being more important than concerns for the environment (Tregear, et al., 1994; Wandel and Bugge, 1997). According to Magnusson et al. (2003) health and environmental motives differ from each other because the health concern can be regarded as anthropocentric or egoistic (benefits to the individual or his/her family) while consideration for the environment and animal welfare are rather altruistic (benefits to society rather than the individual).

According to Saher et al. (2006), there are indications that opinions about organic farming are from an intuitive nature, with supporters not relying on scientific facts but on personal experiences, convictions and beliefs. As explained by Saher et al. (2006), rational and intuitive thinking are the two orthogonal types of information processing, with rational thinking being defined as emotion-free, evidence based reasoning, and intuitive thinking predominantly as building on information sources such as personal experiences and feelings. Given the current lack of systematic scientific evidence arguing in favour of organic credence characteristics, consumers indeed have little other options than to form intuitive quality expectations.

Verhoef (2005) investigated to what extent economic variables (such as price, quality), emotions, social norms and environmental attitudes could explain purchase intention and purchase frequency of organic meat. He concluded that perceived quality positively influences the purchase intention, while purchase frequency is not affected by quality 
perception. He furthermore finds that green behaviour only weakly influences purchase intention and not results in increased purchase frequency. As indicated by Roberts et al. (1996) and Wong et al. (1996), the majority of people are not prepared to compromise on other functional characteristics like quality and convenience for a better environment.

This study tests whether and to what extent consumers perceive organic products as healthier and more environmentally friendly than conventional products. We also test whether consumers consider health traits more important than environmental traits. Therefore, a choice experiment with an organic carrot label and two conventional carrot labels containing the same set of quality traits was presented to a sample of Flemish consumers. Relevant search and experience attributes were assumed identical for the three carrot labels. One of the two conventional carrot labels represents a non-branded or generic product, cheaply priced with base level credence attributes.

The main objective of this paper is thus to analyse whether health and environment related credence attributes are intuitively associated more with organic than with conventional products.

The experiment also allows to test whether the perception concerning these credence attributes differs between organic user groups, as some consumers buy organic more often than others. To reach the traditionally small group of heavy users, choice based sampling was applied. The following hypotheses, derived from the literature cited above, are tested:

1. Consumers prefer health over environment related quality traits;

2. The organic label plays a significant role in shaping consumers' choice for organic products;

3. Vegetables from organic farming are perceived as healthier and more environmentally friendly than vegetables from conventional farming;

4. Purchase intention (buying or not buying organic products) is mainly driven by health related quality traits;

5. Both health and environmental issues influence purchase frequency, though to a different extent.

\section{Materials and methods}

\section{Methodology}

To test the above hypotheses we make use of a stated choice preference experiment and modelling. In such an experiment consumers are placed within a hypothetic choice setting environment in which they are asked to choose their most preferred alternative from a predefined set of alternatives with certain characteristics. The technique makes use of the random utility hypothesis, which states that individual agents choose among the available alternatives the one that maximises their utility and that the distribution of choices made in a population is a reflection of the distribution of individual preferences. The basic choice model is the Multinomial Logit model. An extension to the Multinomial Logit model is the Nested Logit model, which allows to test whether the choice process is sequential, i.e. in the present case, first based upon organic or not and within this choice upon the remainder attributes. Another extension, the Latent Class model, allows to test whether the different user groups perceive the presented attributes differently, without imposing that the sample is split into subsets. In this procedure, individuals are implicitly sorted into a set of Q classes, but which class contains any particular individual, whether known or not to that individual, is unknown 
to the analyst (Greene and Hensher, 2002). Detailed background information on the applied methodologies and the experimental setup is presented in Appendix 1.

\section{Experimental setup}

A choice experiment with three alternative labels was presented to the participants in a consumer survey on organic vegetable consumption. This survey was conducted in Flanders, Belgium during Winter 2007. In total 1,200 questionnaires were distributed from which 553 were returned and 529 were useful for statistical analysis (which corresponds to a valid response rate of $44 \%)$.

To reach the group of heavy users of organic products, 600 of the 1,200 questionnaires were sent to randomly selected members of the Association for Ecological Life and Production style (VELT), of which 270 were returned. VELT-membership is a proxy of greener consumption behaviour, and is intimately related to organic consumption.

The remainder questionnaires were distributed to a sample representative for the Flemish consumer population through a convenience non random sampling procedure. The average age of the sampled consumers (46.6 years) was slightly older than the Flemish average (40.2 years, NIS, 2005). All participants were involved in food purchasing decision-making. The sample was biased towards higher education $(59.9 \%$ in the sample, versus $32 \%$ in the population (NIS, 2005). The sample is for the remainder of the socio-demographic characteristics representative for the Flemish population.

The total sample was split into four user groups, based upon the reported share of organic vegetables in the participant's total vegetable purchases (Table 1).

Table 1. Division of the total sample into user groups based upon organic share in total vegetable purchases

\begin{tabular}{|l|c|c|}
\hline & Organic share $\mathrm{x}(\%)$ & Percentage (frequency) \\
\hline Non user & $\mathrm{x}=0$ & $8.9(47)$ \\
\hline Light user & $0<\mathrm{x} \leq 20$ & $21.4(113)$ \\
\hline Medium user & $20<\mathrm{x} \leq 80$ & $47.1(249)$ \\
\hline Heavy user & $\mathrm{x}>80$ & $22.7(120)$ \\
\hline
\end{tabular}

Carrots were selected as the carrier vegetable, due to their popularity, well known quality traits (such as a high $\beta$-carotene content) and availability both as raw or processed in the organic and conventional version. The presented carrot labels mentioned the product price per $\mathrm{kg}$, as well as health and environment related product traits and a label (organic, conventional A and conventional B). Due to the difficulty for consumers to attach (and retain) meaning to product attributes such as biodiversity, nitrate leaching or $\beta$-carotene content, we combined carrier symbols familiar to consumers (see Figure 1) with these attributes, such as a dung cart for nitrate losses or pictures of rare birds for signalling biodiversity. 


\section{Choiceset 2 a}

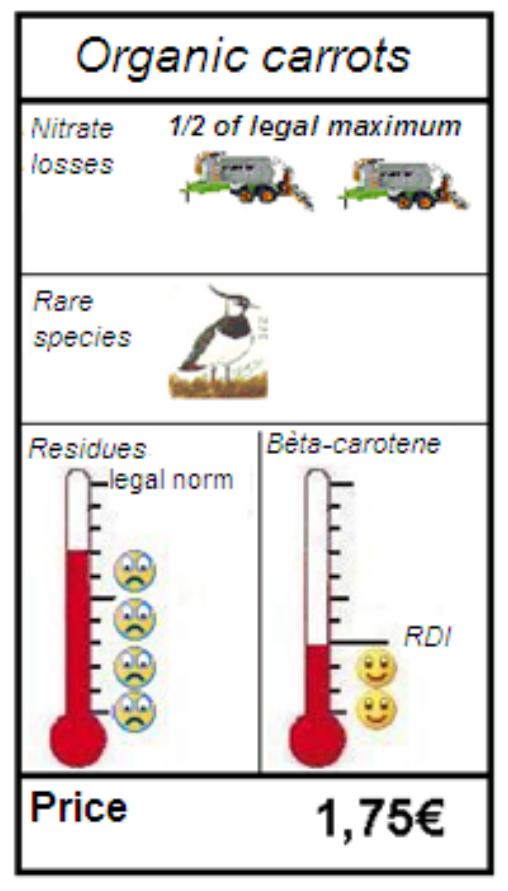

You choose?

Organic

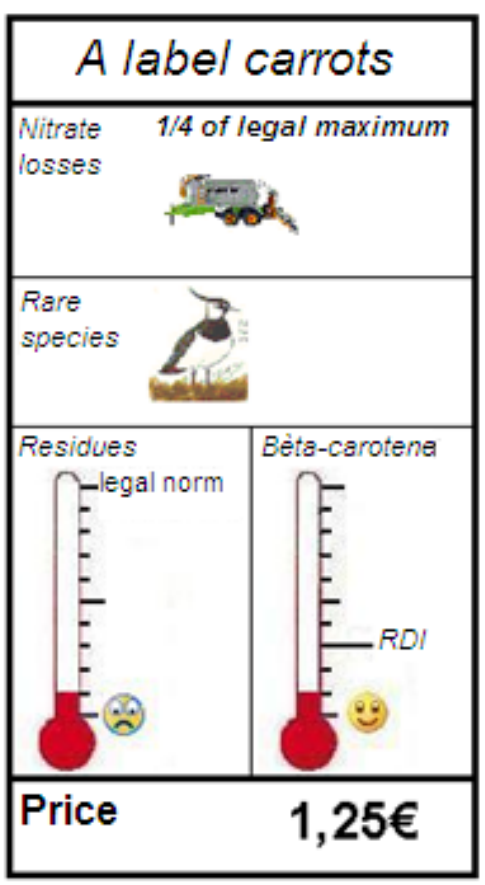

A label

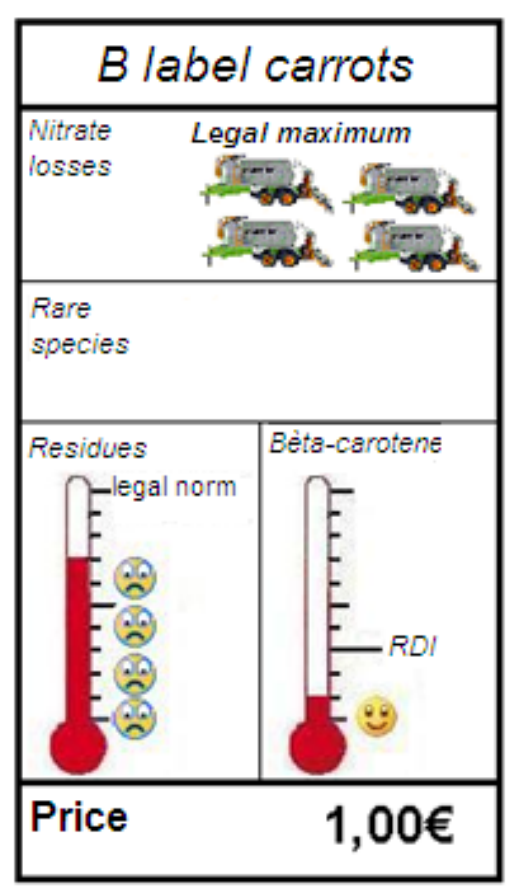

B label

Figure 1. Example of the visual representation of one of the 64 choice sets with the organic, the $A$ and the B-label and their characteristics.

An 'opt out'-choice was not incorporated to avoid an 'easy way out' for consumers that are facing decision difficulty (Kontoleon and Yabe., 2003), although it has been recommended by some recent state of the art choice experiment design guidelines (Louvière et al., 2000 or Adamowicz and Boxall, 2001). Instead, we incorporated a fixed conventional B scenario, which reflects the cheapest option available in the market, with the least interesting product traits. From a theoretic point of view, this B scenario provides us with an anchor point given that, by their nature, utility estimates are estimates of differences in utility. A zero utility is associated with this B scenario, enabling us to interpret the utility estimates of the remainder alternatives and attribute levels relative to these of the fixed B scenario. Both price and other product attribute levels varied over the two remaining alternatives in each choice set. As can be seen in Table 2, four linearly related levels were assigned to each product attribute.

Table 2. Attributes and attribute levels in the choice experiment

\begin{tabular}{|c|c|c|c|c|c|c|}
\hline Quality Trait & ** & Attribute & Level 1* & Level 2 & Level 3 & Level 4 \\
\hline & - & Price & $1.00 €$ & $1.25 €$ & $1.50 €$ & $1.75 €$ \\
\hline & + & Label & ORGANIC & $\mathrm{A}$ & $\mathrm{B}$ & \\
\hline Environment & - & $\begin{array}{l}\text { Nitrate leaching on } \\
\text { the farm site }\end{array}$ & $\begin{array}{l}\text { Legal } \\
\text { maximum }\end{array}$ & $\begin{array}{l}3 / 4 \text { of legal } \\
\text { maximum }\end{array}$ & $\begin{array}{l}1 / 2 \text { of legal } \\
\text { maximum }\end{array}$ & $\begin{array}{l}1 / 4 \text { of legal } \\
\text { maximum }\end{array}$ \\
\hline Environment & + & $\begin{array}{l}\text { Biodiversity on the } \\
\text { farm site }\end{array}$ & $\begin{array}{l}3 \text { rare bird } \\
\text { species }\end{array}$ & $\begin{array}{l}2 \text { rare bird } \\
\text { species }\end{array}$ & $\begin{array}{l}1 \text { rare bird } \\
\text { specie }\end{array}$ & $\begin{array}{l}0 \text { rare bird } \\
\text { specie }\end{array}$ \\
\hline Health & - & $\begin{array}{l}\text { Residue level ( } \% \text { of } \\
\text { MRL) }\end{array}$ & 10 & 30 & 50 & 70 \\
\hline Health & + & Vitamin content & $1 / 2 \mathrm{RDI}$ & RDI & $1,5 \mathrm{RDI}$ & 2 RDI \\
\hline
\end{tabular}

*Level 1 is also the base scenario flagged as the B-label

** Expected utility change when level increases

$\mathrm{MRL}=$ Maximum Residue Limit; RDI = Recommended Daily Intake

For each of the two quality traits (health or environment), two attributes were included in the choice experiment, of which one triggers desirable (positive) expectations and the other 
undesirable (negative). The choice of the attributes (and their levels) was the result of careful deliberation between the choice experiment preconditions and objective scientific boundaries, the latter based upon an extensive literature review (Hoefkens et al., 2009 and Mondelaers et al., 2009).

The first health attribute assesses consumers' sensitivity to residues in carrots. To obtain realistic levels, we departed from the Cadmium levels currently measured in conventional and organic carrots (Figure 2). The maximum level corresponds to $70 \%$ of the Maximum Residue Limit (MRL), the minimum level to $10 \%$.

The second health related attribute, the $\beta$-carotene content, is desirable and relates to the nutritive value of carrots. $\beta$-carotene is the precursor of vitamin A. The Recommended Daily Intake (RDI), expressed in $\mu \mathrm{g} /$ day, is situated between 3,000 en 6,000 (IOM, 2001). The selected boundaries for the choice experiment were 2,000 and 8,000 $\mu \mathrm{g}$ carotene per $\mathrm{kg}$ carrots (or in case of a RDI of 4,000, $1 / 2$ of the RDI to 2 times the RDI), which corresponds well with the real levels of $\beta$-carotene in carrots, whether conventional or organic (Figure 3 ).

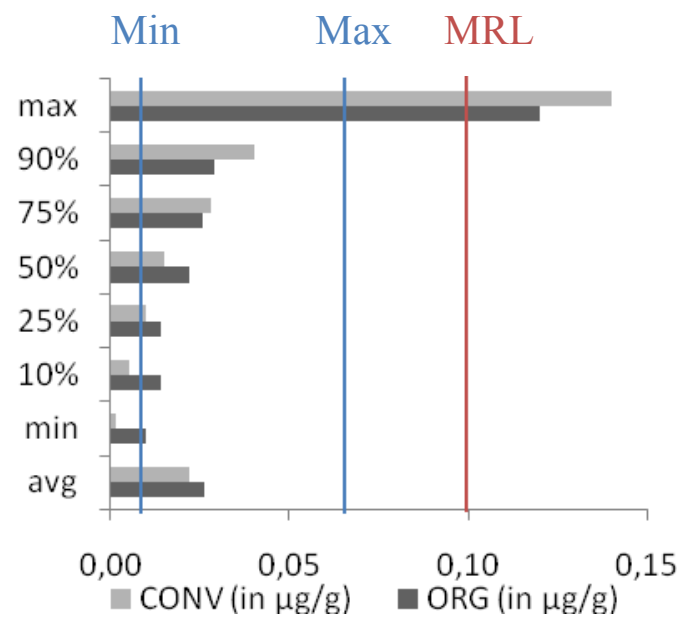

Figure 2. Cadmium levels in organic and conventional carrots (Hoefkens et al., 2009). The choice experiment boundaries are indicated in blue and the Maximum Residue Limit (MRL) in red.

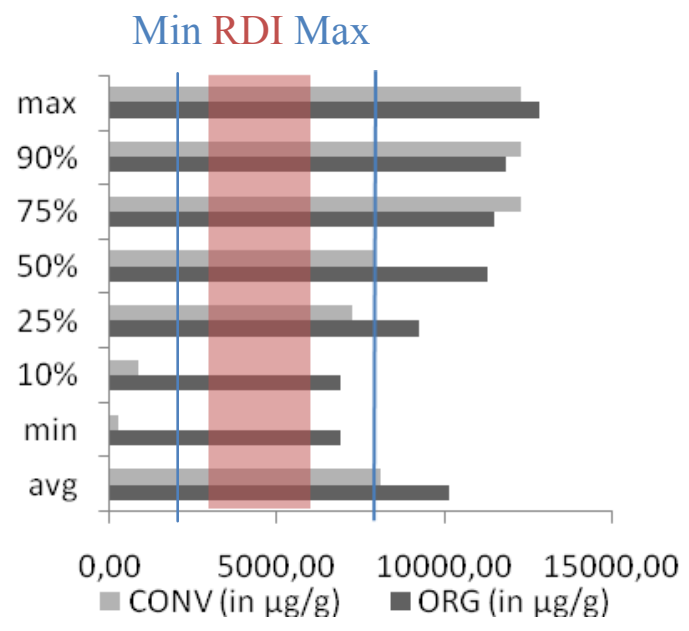

Figure 3. $\beta$-carotene levels in organic and conventional carrots (Hoefkens et al., 2009). The choice experiment boundaries are indicated in blue, the Recommended Daily Intake (RDI) in red.

The first environment related attribute is the number of rare bird species on the farm, which is desirable and is a proxy for biodiversity on the farm. From the 40 Flemish bird species on the list of threatened species, 10 are bound to agricultural areas (Platteau et al., 2005), of which five decreased since 1990 with more than fifty percent. The lower boundary of this proxy was set to zero rare species on the farm, and the upper boundary to three rare species.

As an undesirable environmental trait nitrate leaching on the farm site was selected, given the importance of the nitrate problem in agricultural areas in Flanders. As documented by Mondelaers et al. (2009), nitrate leaching levels on organic and conventional farms varied between 0 and $152 \mathrm{mg} \mathrm{N} / 1$, the latter being an outlier. The EU directive 1991 prescribes a maximum nitrate leaching level of $50 \mathrm{mg} \mathrm{N} / 1$. The attribute levels were based upon this limit and varied from $1 / 4$ of this limit to the actual limit.

The health and environment related traits described above, as well as the price attribute, varied in a similar way for the organic and the A-label, while the B-label attributes were fixed (see Table 2, level 1). The six year average prices for carrots in the retail outlets vary between 
$0.76 € / \mathrm{kg}$ for conventional carrots to $1.38 € / \mathrm{kg}$ for organic carrots (prices from 2001 to 2006, GfK panel data, 2007), which represents a relative price difference of $80 \%$ and which corresponds well with the presented price range of 1 to $1.75 € / \mathrm{kg}$ in the choice experiment. The price attribute was introduced to be able to assess the willingness to pay (WTP) for different tested attributes.

\section{Empirical findings}

\section{Importance of label and quality traits: base model using MNL}

In the first analysis, the sample is restricted to the non-VELT members in order to provide an estimate for the overall Flemish population. The most simple model assumes generic $\beta$ parameters for the different quality traits and a linear relation between the attribute levels. The average unobservable variation between the three alternatives can be captured by means of an alternative specific constant for the organic and the A label carrots. The results are reported in Table 3.

The utility of the B label name is arbitrarily set to zero. The B label with its negative credence attributes receives a negative utility of -4 .44. If we arbitrarily set the full $\mathrm{B}$ alternative to zero, the organic label with the same characteristics receives a positive utility score of 0.972 . First, consumers on average reacted positively on the presence of a label. This signals that consumers attribute quality traits other than those mentioned in the experiment to the labelled carrots. However, unexpectedly, they are quite indifferent whether the label is 'Organic' or simply 'A'.

Table 3. Estimation of choice parameters $\beta$ : generic model with linear attribute levels

\begin{tabular}{l|l|c|c|c|c|}
\hline Attribute & $\beta$-coefficient & Standard error & $\mathrm{P}[\beta \neq 0]$ & $\mathrm{WTP}(€)$ \\
\cline { 2 - 5 } & Organic label & 0.972 & 0.199 & 0.0000 & 0.54 \\
A label & 0.856 & 0.201 & 0.0000 & 0.48 \\
Nitrate leaching & -1.379 & 0.194 & 0.0000 & $0.08^{*}$ \\
Vitamin A & 0.471 & 0.090 & 0.0000 & $0.03 * *$ \\
Biodiversity & 0.165 & 0.044 & 0.0002 & $0.01^{* *}$ \\
Residue & -2.150 & 0.234 & 0.0000 & $0.13 *$ \\
Price & -1.791 & 0.187 & 0.0000 & \\
\hline
\end{tabular}

Second, the model confirms our prior expectations on desirable and undesirable quality traits. 'Nitrate leaching' and 'Presence of residues' trigger negative consumer responses, while 'More biodiversity' and 'Vitamin A content' are perceived as positive, and thus desirable. The price component is furthermore negative and significant, as can be expected. Third, these results indicate a perceived higher disutility for the negative quality traits compared to the positive. This finding confirms that consumers react more heavily to undesirable stimuli than to desirable stimuli (Verbeke, 2005), identified by Kahneman et al. $(1990,1991)$ as the endowment effect which explains why economic agents attach a higher value to potential losses than gains.

The attributes themselves need to be taken into account as well, because there might be an imbalance (i.e. one attribute might be too dominant compared to the others). An increase in residue content from 50 to $70 \%$ of the MRL is considered four times less desirable than a decrease in vitamin A content with $1 / 2$ of the RDI. Thus, consumers indeed seem to be much more sensitive to attributes that relate to food safety risks than to nutritional benefits. Fourth, 
the first hypothesis that health related issues will trigger a stronger consumer response than environmental issues, can be confirmed when comparing the negative health attribute 'Residues' with the negative environment attribute 'Nitrate leaching', or the positive trait 'Vitamin A' with 'Biodiversity'. However, the 'Nitrate leaching'-attribute has a stronger influence than the positive health attribute 'Vitamin A'-content. Apart from the endowment effect mentioned above, a plausible explanation is the fact that consumers probably correlate nitrate leaching with nitrate content in the carrot, which is again an undesirable food safety attribute. The nitrate leaching problem has also received considerable media attention in Flanders in recent years.

\section{Willingness to pay estimates}

The ratio of a variable of interest and the monetary variable will yield a monetary value for a change in the attribute level of the variable of interest, as far as the latter variable is statistically significant (Hensher et al., 2005). In our choice experiment the price attribute is highly significant, as well as the other attributes. WTP's can thus be calculated for these attributes, using the formula: $-\beta_{\mathrm{x}} / \alpha$ with $\beta_{\mathrm{x}}$ being the taste parameter of the $\mathrm{x}^{\text {th }}$ attribute (in 'utils' per unit of attribute $\mathrm{x}$ ) and $\alpha$ the taste parameter of the premium (in 'utils' per unit of premium).

We start from a carrot price of $1 € / \mathrm{kg}$ for the B-labelled carrots, which corresponds well with the current price level in real markets. As reported in Table 3, the average extra WTP for a $\mathrm{kg}$ of carrots labelled 'Organic' or ' $\mathrm{A}$ ' is $0.54 €$ and $0.48 €$, respectively, which means $50 \%$ extra. The question is now whether we may assume that the average price premium consumers are willing to pay for organic vegetables is $50 \%$ or whether we have to take the 'A'-label price as a reference and conclude that there is no willingness to pay extra for organic carrots in our experiment. This will be explored in subsequent sections, but our findings support the hypothesis that organic vegetables are by a majority of respondents merely perceived as quality niche products. The WTP for a $10 \%$ reduction in residues (within the boundaries of the experiment) amounts to $0.125 €$, or $12.5 \%$ extra. For a $10 \%$ reduction in nitrate leaching, the average WTP is $8 \%$ extra. WTP's for positive traits are considerably smaller, 0.03 and $0.01 €$ for a $10 \%$ increase in vitamin A content and biodiversity on the farm site, respectively.

\section{Relation between label and quality traits}

The previous model assumed linearity of the attribute levels and generic choice parameters. Wald tests for restrictions argue in favour of the first assumption. The estimation of a model with alternative specific choice parameters for the organic carrots yields a log likelihood of 752 , which is significantly better than the previous model, as confirmed by the log likelihood test $\left(39.07>11.07=x_{0}^{2}\right)$. This new model supposes a different response from consumers whether the quality trait is presented on an organic versus conventional package. The insignificant $\beta$-estimate for the organic label indicates that consumers, on average, choose organic carrots based upon the quality attributes and not on the label name (Table 4). It means that respondents did not take any additional attribute into account than those mentioned in the experiment, or, put differently, the positive attitude towards organic products is linked to the health and environment related quality traits of organic products. Thus, although the label itself does not trigger a positive utility score, it does so indirectly through better scores for the remaining attributes. The A-label on the contrary is significant and positive, thus it triggers higher quality expectations than the name B or organic, and these expectations relate to other attributes than those mentioned in the experiment. Interestingly, a difference in biodiversity is not an issue when the conventional carrot is preferred, as can be seen from the insignificant $\beta$ estimate. 
Table 4. Estimation of choice parameters $\beta$ : model with linear attribute levels and alternative specific $\beta$ parameters for the organic carrots

\begin{tabular}{|l|c|c|c|}
\hline Attribute & $\beta$-coefficient & Standard error & $\mathrm{P}[\beta \neq 0]$ \\
\hline Organic label & -0.741 & 0.658 & 0.2601 \\
Org. Nitrate leaching & -1.234 & 0.259 & 0.0000 \\
Org. Vitamin A & 0.421 & 0.132 & 0.0015 \\
Org. Biodiversity & 0.373 & 0.066 & 0.0000 \\
Org. Residue & -1.384 & 0.317 & 0.0000 \\
Org. Price & -1.927 & 0.270 & 0.0000 \\
\hline A label & 0.773 & 0.256 & 0.0026 \\
Nitrate leaching & -1.697 & 0.275 & 0.0000 \\
Vitamin A & 0.644 & 0.132 & 0.0000 \\
Biodiversity & -0.070 & 0.067 & 0.2941 \\
Residue & -3.216 & 0.353 & 0.0000 \\
Price & -2.097 & 0.268 & 0.0000 \\
\hline B label* & 0.000 & \multicolumn{3}{|c|}{} \\
\hline \multicolumn{4}{||}{ *arbitrary set to $0 ; \mathrm{N}=1024 ; \mathrm{LogL}=-751.90 ; \chi_{(10)}^{2}=310$}
\end{tabular}

The organic carrots trigger less extreme reactions than the conventional (e.g. lower disutility for nitrate leaching but also lower utility for vitamin A). As such, two carrots with the same quality traits (e.g. the most positive attribute levels), one being organic, the other an A label carrot, yield similar utility scores (as also confirmed by the previous model).

\section{Purchase intention and frequency}

To explore the difference in preference structure between consumers who frequently buy organic and those who don't, the full sample with the different user groups can be used. We build further on model 1, assuming generic (i.e. not alternative specific) parameters for the health and environmental quality traits and linearly related attribute levels.

To test the hypothesis that purchase intention for organic vegetables is triggered by other traits than purchase frequency, we compare the model estimates of the non user group with those of the user group (Table 5). Findings indicate that the purchase intention of the non user group is mainly based on the quality traits price and food safety (residue content), while the decision process of the user group is more complex and also involves environmental traits and the label name. As expected, both the price and residue attribute trigger a strong negative utility response. The non users are the only user group where the attribute 'Residues' is not the least preferred. The insignificance of the attributes in the non user model, except for residue and price, might be partly due to the small group size $(n=47)$. On the contrary, price and residue content are highly significant, so these are clearly the main decision variables in this group.

Table 5. Influence of purchase intention: $\beta$-parameters for non users versus users

\begin{tabular}{|l|c|c|c|c|c|c|}
\hline & \multicolumn{3}{|c|}{ Non User } & \multicolumn{3}{c|}{ User } \\
\hline Attribute & $\beta$-coefficient & s.e. & $\mathrm{P}[\beta \neq 0]$ & $\beta$-coefficient & s.e. & $\mathrm{P}[\beta \neq 0]$ \\
\hline Organic label & 0.397 & 0.413 & 0.337 & 1.546 & 0.179 & 0.000 \\
A label & 0.425 & 0.423 & 0.316 & 1.115 & 0.183 & 0.000 \\
Nitrate leaching & -0.749 & 0.473 & 0.113 & -1.397 & 0.148 & 0.000 \\
Vitamin A & 0.340 & 0.230 & 0.139 & 0.462 & 0.066 & 0.000 \\
Biodiversity & 0.140 & 0.116 & 0.228 & 0.239 & 0.033 & 0.000 \\
Residue & -2.583 & 0.606 & 0.000 & -2.463 & 0.177 & 0.000 \\
Price & -2.999 & 0.485 & 0.000 & -1.265 & 0.137 & 0.000 \\
B label* & 0.000 & & & 0.000 & & \\
\hline
\end{tabular}

*arbitrary set to 0

Model 'non users': $\mathrm{N}=188 ; \operatorname{LogL}=-157,9 ; \chi^{2}{ }_{(5)}=73$

Model 'users': $\mathrm{N}=1900 ; \operatorname{LogL}=-1254,8 ; \chi^{2}{ }_{(5)}=466$ 
The parameter estimates as depicted in Figure 4 reflect the preference of the light, medium and heavy user groups for the product attributes in the experiment.

For the light users, all attributes are significant, except the environmental attribute 'Biodiversity'. All estimates have the expected sign and the negative health and environmental traits have a higher utility compared to the positive characteristics. For this user group, the organic or A-label are equally important (as confirmed by the Wald test) and both trigger a positive utility. The medium users are the only user group taking all the attributes into consideration, including the biodiversity item. Compared to the non user and light user groups, the utility of the price attribute decreases further, while both the A and organic label gain importance. The label 'Organic' furthermore receives a significantly higher utility estimate than the A-label, as confirmed by the Wald test. The heavy user group finally is the only group where the price attribute is insignificant, i.e. within the price fork of $1 €$ to $1.75 €$, the heavy user is price insensitive. The remainder of the attributes are in line with those of the medium user group, apart from the value attributed to the label name 'Organic', which is among heavy users twice as important as the A-label, indicating that heavy users choose in most cases the organic product irrespective of the other quality attributes.
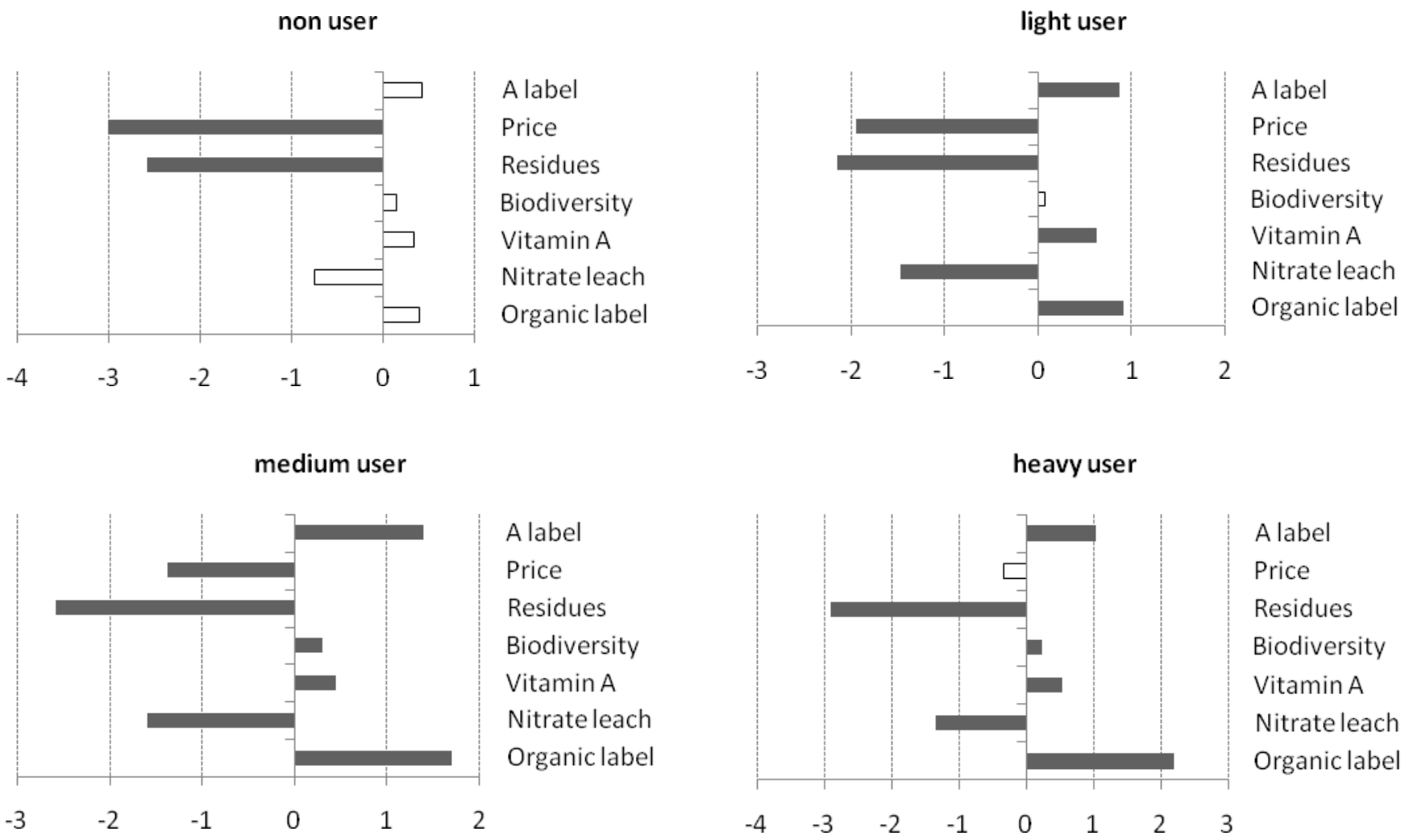

Figure 4. Choice parameters for the choice attributes per user group. White bars indicate estimates insignificant at the 5\% level. Model 'non users': $N=188 ; \log L=-157,9 ; \chi^{2}(5)=73 ;$ Model 'light users': $\mathrm{N}=452 ; \log \mathrm{L}=-340,1 ; \chi^{2}(5)=117 ;$ Model 'medium users': $\mathrm{N}=980 ; \operatorname{LogL}=-612.2 ; \chi^{2}(5)=277 ;$ Model 'heavy users': $\mathrm{N}=468 ; \log \mathrm{L}=-\mathbf{2 5 0}, 2 ; \chi^{2}(5)=105$

\section{Latent Class analysis}

A more advanced way of measuring parameter heterogeneity across individuals is the Latent Class model, in which the individual resides in a latent class, not revealed to the analyst (Greene, 2007). Estimates consist of the class specific parameters and for each subject a set of 
probabilities is defined over the classes. Although class membership is not observed, observable characteristics can be introduced that help to achieve class separation, such as organic user group in this particular study. The advantage of this approach compared to the above arbitrary division of the sample in subsamples is that all the information contained in the sample is used to estimate the class models instead of the limited information contained in the subsample. Table 6 shows the results for the Latent Class model in which the variable "organic user group" was used as the observable characteristic. The model with two classes is optimal, since the parameters of the models with more classes inflate rapidly. The likelihood of the model (-1318) is significantly better than the model without the latent classes $(-1510)$, as confirmed by the likelihood ratio test.

Table 6. Latent class estimation of choice parameters $\beta$ : model with linear attribute levels and alternative specific $\beta$-parameters for the organic carrots

\begin{tabular}{|l|c|c|c|c|c|c|}
\hline & Latent class 1 & \multicolumn{2}{l|}{ Latent class 2 } \\
\hline Attribute & $\beta$-coefficient & Standard error & $\mathrm{P}[\beta \neq 0]$ & $\beta$-coefficient & Standard error & $\mathrm{P}[\beta \neq 0]$ \\
\hline Organic label & 3.964 & 1.102 & 0.000 & 4.728 & 1.328 & 0.000 \\
Org. Nitrate leaching & -1.591 & 0.207 & 0.000 & -0.462 & 0.496 & 0.351 \\
Org. Vitamin A & 0.551 & 0.102 & 0.000 & -0.220 & 0.262 & 0.402 \\
Org. Biodiversity & 0.299 & 0.501 & 0.000 & 0.185 & 0.115 & 0.107 \\
Org. Residue & -2.262 & 0.254 & 0.000 & -2.260 & 0.707 & 0.001 \\
Org. Price & -0.848 & 0.211 & 0.000 & -8.749 & 0.746 & 0.000 \\
\hline A label & 4.103 & 1.005 & 0.000 & 1.709 & 0.419 & 0.000 \\
Nitrate leaching & -1.411 & 0.217 & 0.000 & -0.264 & 0.502 & 0.600 \\
Vitamin A & 0.455 & 0.100 & 0.000 & 0.623 & 0.253 & 0.014 \\
Biodiversity & 0.219 & 0.051 & 0.000 & -0.161 & 0.121 & 0.181 \\
Residue & -3.057 & 0.276 & 0.000 & -0.866 & 0.622 & 0.164 \\
Price & -0.984 & 0.202 & 0.000 & -7.123 & 0.706 & 0.000 \\
\hline B label & 0.000 & \multicolumn{7}{|c|}{0.000} & 0.000 & \\
\hline
\end{tabular}

In the first class, which has $86 \%$ probability that a respondent resides in this class, all parameters are significant and in line with our previous estimates. The label name has become a more decisive characteristic, opposite to the price level whose importance has decreased compared to the model without latent classes. These results indicate that the members of this first class choose against the B scenario, regardless of the price difference. Both the A alternative and organic alternative have similar parameter estimates, so the respondents are rather indifferent between both.

In the second class, with an average probability of $14 \%$, the parameters for the majority of the credence attributes are insignificant. The organic label again receives a high and positive score, while the score of the A label is considerably lower. Furthermore, the price parameter is very negative in this group. This group can therefore be considered as very price sensitive consumers. Main decision variables for these consumers are thus price and presence of the organic label, the rest of the attributes are hardly relevant for them. Further analysis shows that this class is mainly composed of individuals that (at least once) chose the B alternative as their preferred alternative.

\section{Heterogeneity between alternative choice patterns: the Nested Logit model}

How do consumers process the different labels? Do they first decide based upon the organic label name and then upon the remainder attributes (Figure 5 left), or do they first decide based upon the quality level and then upon the remainder attributes (Figure 5 in the middle), or do they simply process all quality attributes and the label name simultaneously (Figure 5 on the right)? A Nested Logit model, which compares the variation in the two different branches of the models in Figure 5, allows for testing these alternative scenarios. Considering the tree 
model on the left, one could assume that consumers process both the A and B label in a similar way, which differs from the way they process the organic label. This yields one organic branch and one conventional decision branch. If both branches are statistically equal than the consumer processes all attributes simultaneously (right case). If the consumers focus on quality versus generic products, we obtain the tree structure in the centre of figure 5.
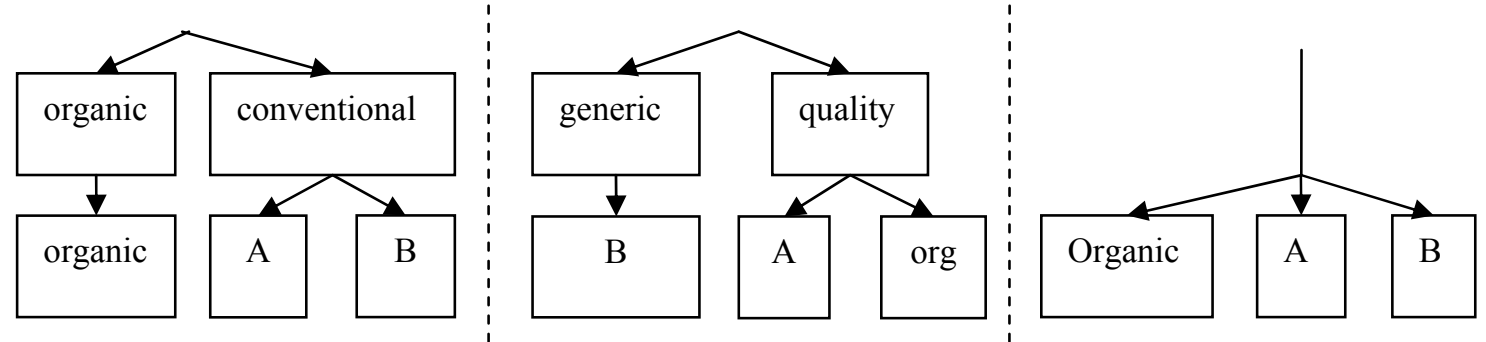

Figure 5. Nested Logit models for the choice experiment. Left: organic processed differently than conventional, Middle: quality products processed differently than generic product, Right: no prioritisation

Both for the sample reflecting the Flemish consumer population and the sample of VELT members, Wald tests show that the variation in each of the branches is not statistically different (the inclusive values IV are similar), so the model on the right is the appropriate one for the full sample. Consumers thus generally process the information on the three alternatives in a similar way.

However, the Latent Class model hinted that both groups process the labels differently. If we split the overall sample into two groups based upon highest class probability, we can test the nested models on the subsamples. Regrettably, Nested Latent Class Logit models are not yet operationally developed, so we have to follow this procedure. For both classes the 'quality versus generic' model is the most appropriate (Figure 5 in the middle). The inclusive value (IV) for the generic branch is assumed fixed at 1, to enable testing of IV of the quality branch. For the members of latent class 1 , the IV of the quality branch is not significantly different from zero, which indicates that we should consider two different models for this group, i.e. one model for the comparison of label A and Organic and one for the B label, as depicted in Figure 6. As the B label is almost completely ignored by this group, it can reasonably be assumed that the class 1 members only consider the A and Organic label. Hence, a Binary Logit model could be appropriate to describe this group.

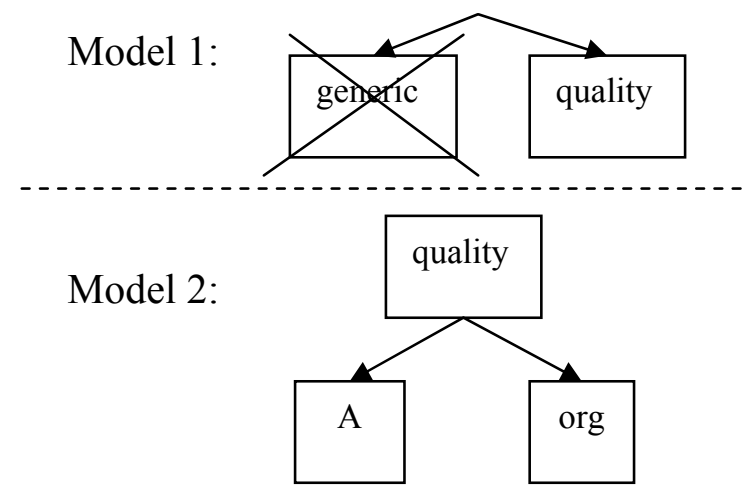

Figure 6. Decision model for members of latent class 1

For the second latent class, the IV of the quality branch differs significantly from zero and from 1, which indicates that the nested model is the appropriate one. Members of this group thus intuitively cluster the A and Organic label versus the B label before deciding. 


\section{Discussion and conclusion}

Because the experiment's attribute levels have been based upon real levels currently observed in the market place, our approach to compare the attributes one to another is reasonable. We do not wish to make any statement of the importance of these attributes versus other search and experience attributes such as taste, colour, shape and smell. To test the latter, the experimental design should be different.

Our first hypothesis, 'health traits are more important during the buying decision than environmental quality traits', could not be fully confirmed, given the relatively high score for the attribute 'nitrate leaching on the farm site'. Instead we noted that undesirable traits trigger a stronger response than desirable traits. Within these negative or positive response classes, the health related variables score 'better' than environment related variables. This might argue for a decision tree in which the first trade off is made in favour of 'avoiding an undesirable outcome' and the second in favour of the 'personal health benefit compared to the environmental benefit'. The food safety related 'residue'-item yields the heaviest consumer reaction. This can be reasonably explained by the prospect theory of Kahneman and Tversky (1979), which argues that consumers prefer avoiding risks to capturing gains.

Our second hypothesis, 'the organic label plays a significant role in consumers' choice for organic products', can only partly be confirmed. Consumers do prefer organic products over B-labelled products, but not over A-labelled products, which argues for the consideration that most consumers classify organic products among other 'quality niche products'. However, in response to hypothesis 3, 'organic farming is perceived as healthier and more environmentally friendly than its conventional counterpart', consumers define the quality traits differently between both the organic and the A-label. Organic and the A-labelled carrots in the experiment with the same health and environmental characteristics obtain a similar total utility score, while the individual choice parameter scores for the health and environmental attributes are higher for the organic carrot variant. This means that the respondents relate the quality of organic vegetables to the attributes mentioned in the experiment, while the A-label quality traits are mainly absorbed in the positive A label specific constant, and thus may cover other attributes not mentioned in the experiment.

The fourth hypothesis, which states that purchase intention is primarily based upon quality traits, can be confirmed. The attributes of influence for those who do not buy organic are restricted to food safety and price, while those who buy organic also attach value to the label name and the environmental attributes.

The fifth hypothesis explores whether in our experiment buying frequency and the presence of environmental and health traits are correlated. Apart from the insignificant biodiversity proxy in the case of light users, this does not seem to be the case. However, over the different user groups, two other, albeit opposite, trends can be detected. The first relates to price, which shows a decreasing importance from non to heavy users. This confirms the finding of other studies (O'Donovan and Mc Carthy, 2002, Bonti-Ankomah and Yiridoe, 2006) that the perceived price difference is the most important barrier for new users to buy organic or for light users to increase their purchase of organic foods. Among heavy users, the price is not an issue, at least within the experiment's price range. The second trend relates to the (organic) label value, which increases from non to heavy users, indicating that when the buying frequency of organic vegetables increases, more unobserved preference attributes (which could relate to taste or appearance) are associated with the organic label.

The more advanced Latent Class and Nested Logit model confirm the importance of the price when purchasing food. The group of consumers which is extremely price sensitive, associates a higher utility with the organic label compared to the A-label. This suggests that these consumers are aware of the specialty character of organic vegetables. However, owing to the high perceived price premium, they favour non organic products. Presence of residues in the 
organic carrots is not appreciated, probably because this is against the 'organic philosophy'. The large group of less price sensitive consumers on their turn processes both the A and organic label in a similar way, i.e. all attributes are relatively equally important. The organic quality traits receive slightly better scores, indicating that these traits are intrinsically associated more with the organic carrots. The Nested Logit model shows that this group hardly considers the B-label.

We can conclude that there is differential consumer sensitivity for the type and quality of credence attributes and that the organic label is associated more with health and environment related quality traits. To maintain (and reinforce) this perception among consumers and organic product positioning, it is recommended to give this perception additional scientific underpinning.

\section{Acknowledgement}

\section{Appendix: methodological issues}

\section{Random utility theory}

The stated choice preference technique allows an ex ante assessment of both the use and non use value of the main characteristics of a good or service, opposite to revealed preference or contingent valuation, being an ex post analysis method and restricted to goods or services as a whole, respectively. To model choice behaviour by a decision maker (e.g. a consumer), most studies depart from the principles of the Random Utility Theory (McFadden, 1974) and the Characteristics Theory of Value (Lancaster, 1966). The latter states that individuals derive utility from the characteristics of goods rather than directly from the goods themselves. Random utility models are derived from assumptions about individuals' evaluation of goods and services. These assumptions about individuals' behaviour are introduced to account for the researcher's inability to fully represent all variables that explain all preferences in an individual's utility function. The random utility hypothesis states that individual agents choose among the available alternatives the one that maximises their utility and that the distribution of choices made in a population is a reflection of the distribution of individual preferences. Therefore, the probability $\left(\mathrm{P}_{\text {in }}\right)$ that a consumer $\mathrm{n}$ chooses alternative $\mathrm{i}$ (which has an attribute vector $X_{\text {in }}$ ) from a choice set of $J$ alternatives (in our research limited to three) can be written as (1):

$$
\left.P_{m}=P\left(U_{m}\right) \times P\left(U_{m}\right) \text { for } a l l\right) \neq t
$$

This equation indicates that a consumer will choose alternative $i$ in the choice set only when this alternative has the highest utility, compared to the other two alternatives in the choice set. The utility function $U$ can be further decomposed into a deterministic part (V), which is a function of the observed factors (the product quality traits incorporated in the experiment), and a stochastic part $\left(\varepsilon_{\text {in }}\right)$. The latter results from unobservable factors which affect choice, unobservable taste variations, measurement errors in the explanatory variables in function $\mathrm{V}$ and model specification errors. Because the researcher has no knowledge about $\varepsilon_{\text {in }}$, these terms are treated as random, as well as the utility for each alternative.

\section{Multinomial Logit model}

As introduced by McFadden (1974), the indirect utility function is assumed to be linear in the parameters, and as such, takes the form as in equation (2) for an individual $\mathrm{n}$ facing choice $\mathrm{i}$ :

$$
u_{i n}=\alpha_{i n}+\beta_{n}^{l} x_{m}+a_{i n}
$$


The deterministic part can be further decomposed into $\alpha_{\text {in }}$, which is the individual n's intrinsic preference for choice $i, x_{\text {in }}$ the vector of attributes of alternative $i$ in the choice set faced by $n$ and $\beta_{\mathrm{n}}$ the vector of choice parameters, which are the weights associated with the attributes $\mathrm{x}_{\mathrm{in}}$. Depending on the assumptions about the error term, different models can be derived. The most general (and restrictive) model, the Multinomial Logit model, assumes an identical and independently distributed (iid) Gumbel distributed error term (Train, 2003 in Liljenstolpe, 2005), with the following choice probability (equation 3):

$$
P_{n}=\frac{e^{\alpha_{n}+\beta_{n}^{r} x_{n}}}{\sum_{j} e^{\alpha_{n n}+\beta_{n}^{l} x_{m n}}}
$$

As described by Liljenstolpe (2005), the conditional Multinomial Logit probability takes a closed form between 0 and 1, and the unconditional Multinomial Logit probability is derived by summing over all respondents and choices:

$$
L L\left(\alpha_{m}, \beta_{n}\right)=\sum_{n=1}^{N} \sum_{i=1}^{L} y_{m} \ln P_{t n}
$$

The dummy variable $y_{\text {in }}$ takes value 1 for the chosen alternative and 0 for the non-chosen alternatives. From the first order condition of the log-likelihood function, the model coefficients can be estimated.

\section{Nested Logit model}

An extension to the Multinomial Logit model is the Nested Logit model, in which the assumption of iid and Independence for Irrelevant Alternatives (IIA) is relaxed. In the Nested Logit model the alternatives are grouped into subsets, and the variance is allowed to differ across the subsets while the IIA assumption is maintained within the subsets (Shen, 2005). This model allows to test whether the respondent's choice process is sequential, i.e. first based upon one attribute (e.g. organic or not in this study), and within this choice upon the remainder attributes. The assumption is that if the utility functions of two alternatives share a common set of missing attributes, all of which have a similar influence upon the utilities of these two alternatives, then the variance of the unobserved effects for each of those alternatives is likely to be similarly influenced, suggesting that such alternatives are situated in the same branch of a Nested Logit tree (Hensher et al., 2005). If the remainder alternative is influenced by a different set of 'missing' attributes, the variance in its unobserved effects will also differ, providing us with a measure for the appropriate tree structure.

\section{Latent Class model}

The Latent Class Logit (LCL) model is another extension. The underlying theory of the Latent Class model posits that individual behaviour depends on observable attributes and on latent heterogeneity that varies with factors that are unobserved by the analyst. In Latent Class models it is assumed that individuals are implicitly sorted into a set of Q classes, but which class contains any particular individual, whether known or not to that individual, is unknown to the analyst (Greene and Hensher, 2002). The central behavioural model is a logit model for discrete choice among $\mathrm{J}_{\mathrm{i}}$ alternatives, by individual $\mathrm{i}$ observed in $\mathrm{T}_{\mathrm{i}}$ choice situations:

$$
P_{i+i}=\frac{\exp \left(x_{i+}^{s} \beta_{q}\right)}{\sum_{i=1}^{h} \exp \left(x_{t i}^{i} \beta_{q}\right)}
$$

The prior probability for class $\mathrm{q}$ for individual $\mathrm{i}_{\mathrm{iq}}$, can be written as (Greene and Hensher, 2002): 


$$
E_{t q}=\frac{\exp \left(z_{t}^{i} \theta_{q}\right)}{\sum_{i=1}^{q} \exp \left(z_{i}^{i} \theta_{q}\right)}
$$

where $z_{i}$ is a set of observable characteristics determining class membership. The likelihood for individual $i$ is then the expectation over classes of the class specific contributions:

$$
P_{t}=\sum_{q=1}^{Q} H_{i q} P_{i} q
$$

This model allows to test whether the different user groups perceive the presented attributes differently, without imposing that the sample is split a priori into subsets.

\section{Practical implementation in this study}

The analytical procedure followed in this paper is documented in Louvière et al. (2000). A relevant question is: why including a B-label and not an opt-out? As our focus lays with the credence attributes, including an opt out choice would not reveal any additional information, apart from the fact that the decision maker does not favour the presented carrots. As a variation to the opt out, we constructed a B label carrot which mimics the low budget conventional carrots that can be found in any retail outlet. We implicitly make the assumption that the respondent wants to buy carrots. For a respondent indifferent to credence attributes, the B scenario is than equivalent to an opt out. Introducing an additional conventional scenario A enables us to measure how much value the consumers attach to each of the presented credence attributes. Furthermore, introducing the organic variant enables us to measure whether consumers associate the positive credence attributes more with the organic variant than with the conventional variant. As such, the combination of a conventional fixed scenario, a conventional variable scenario and an organic variable scenario is the best option to test our different hypotheses.

The statistical interpretation of the fixed alternative is comparable to the no choice option. The utility for alternative B, including its particular attribute levels, is considered as a constant. We can arbitrarily set this utility to zero and as such measure the preference for the credence attributes and their correlation with the A or Organic alternative relative to the B scenario. As the MNL model is based upon measuring the difference in utility (Hensher et al., 2005), this choice is reasonable. The A label with the worst attribute levels and the B label only differ in name, therefore we can use the scores for the attribute levels of the A label to deduct the score for the B label name separately. This is possible because the attribute levels of $\mathrm{A}$ and $\mathrm{B}$ can be considered as generic, as they both represent conventional carrots. When using dummy coding, the utility score for the zero coded attribute level cannot be separated from the alternative's grand mean (or constant). As we used effects coding instead of dummy coding (see Hensher et al., 2005 or Bech, 2005), the remaining attribute level of each attribute is not confounded with the alternative's grand mean (or the A label in our case). We can thus obtain a score for the label name and for all the attribute levels separately. From the alternative A we can then infer the preference (or dislike in this case) for the attribute levels of alternative B. Subtracting these from the alternative B utility score gives us the intrinsic preference for the B label.

The choice for four attribute levels per attribute enables us to better distinguish non linear effects from linear effects and it also guarantees attribute level balance, as each varying attribute now has an equal number of levels, as recommended by Louvière et al. (2000). The number of levels obviously affects the required sample size. 
A full factorial enumeration of possible combinations of the results into $4^{2 \times 4}$ alternatives. With one alternative fixed (the B scenario), only two alternatives vary per choice set. Each of these carries a label (organic or A). The necessary degrees of freedom is $31(1+5$ attributes $\times 2$ alternatives x (4 levels - 1), Hensher et al., 2005), hence an orthogonal set of 32 profiles is sufficient. To avoid the random recombination of profiles into choice sets, we followed the procedure as documented by Louvière et al. (2000), and constructed an orthogonal set of 64 profiles with 10 attributes and four levels per attribute. The first five attributes relate to the organic alternative, while the last five relate to the conventional A label. We opted for this procedure instead of using foldovers to guarantee orthogonality across and within alternatives. The orthogonality of the design ensures that the attributes presented to individuals are varied independently from one another (zero correlation). This property guarantees that the influence of changes in any of the presented attributes on respondents' choices (or utility) can be measured independently. With the help of statistical software (SPSS) 64 profiles were constructed. The resulting sets were split into blocks of four choice sets per survey, to make the respondent' choice task manageable. Each survey participant was asked which type of carrot he/she would prefer from each choice set, given the three alternatives' characteristics, label and price and as such had to do four times the experiment.

In this experiment we opted for an orthogonal design instead of more efficient designs, such as a D-optimal design, as the latter require a priori knowledge concerning the sign and magnitude of the taste parameters (see Bliemer and Rose, 2003). As Bliemer and Rose (2003) indicate, in cases where one has no information on the parameter estimates whatsoever, it is common practice to assume that the prior parameter estimates are all equal to zero. When only alternative-specific parameters are to be estimated, an orthogonal design will be the most efficient design, assuming that the parameter estimates are zero. Therefore, an orthogonal design will be a good design in a scenario when no prior information is available to the analyst. According to Louvière et al. (2000) and Bliemer and Rose (2003), required sample size can be calculated as:

$$
N \geq \frac{1-p}{S p \alpha^{2}}\left[\Phi^{1}\left(1-\frac{1}{2} \alpha\right)\right]^{2}
$$

with $p$ the true choice proportion of the relevant population, $a$ the level of allowable deviation in percentage, $S$ the number of repetitions per respondent and the inverse cumulative distribution of a standard normal defined by the desired confidence level. If we assume equal proportions for each alternative (i.e. $p=1 / 3$ ), a desired precision $a$ of $10 \%$ (i.e. $10 \%$ deviation around $p$ allowed), a confidence level of $95 \%$ and $S=4$, the required sample size $N$ is 192 . The sample sizes in our study exceed this required size with $\mathrm{N}=266$ for the VELT -group and $\mathrm{N}=256$ for the non VELT-group.

A weighting variable was introduced to correct for disproportional sampling of certain choice sets. The weighting variable is defined as (Louvière, 2008):

$v_{i}=\frac{\text { monage sompling of whatce sets }}{\text { sanving of chaice sei i }}$

\section{References}

Adamowicz, W. and P. Boxall (2001) "Future Directions of Stated Choice Methods for Environment Valuation", Paper prepared for: Choice Experiments: A New Approach to Environmental Valuation, April 10, 2001, London, England. 
Aertsens, J. and Van Huylenbroeck, G. (2008). "Added Value of Organic Farming and Food: consumer perception versus facts". Project financed by ADLO, Final report, December 2007. $\mathrm{http}: / /$ www.agecon.ugent.be/pdf/meerwaarde_eindrapport.pdf

Bonti-Ankomah, S. and Yiridoe, E.K. (2006), "Organic and conventional food: A literature review of the economics of consumer perceptions and preferences", Final Report, Organic Agriculture Centre of Canada, Nova Scotia, 63p.

Chen, M. F. (2007) "Consumer attitudes and purchase intentions in relation to organic foods in Taiwan: Moderating effects of food-related personality traits", Food Quality and Preference, Vol. 18 No. 7, pp. 1008-21.

GfK panel data (2007).

Greene, W.H. (2007). NLogit Version 4 Reference Guide. Econometric Software, Inc., Plainview, USA.

Greene, W.H. and Hensher, D.A. (2002). "A Latent Class Model for Discrete Choice Analysis: Contrasts with Mixed Logit”. Institute of Transport Studies, Sydney, Australia. Working Paper ITS-WP-02-08, ISSN 1440-3501, 18p.

Grunert, K. G. (2002) "Current issues in the understanding of consumer food choice", Trends in Food Science \& Technology, Vol. 13 No. 8, pp. 275-85.

Grunert, K.G., Hartvig Larsen, H., Madsen, T.K. \& Baadsgaard, A. (1996). "Market orientation in food and agriculture", In: Grunert, K.G., Bech-Larsen, T. \& Brendahl, L. (2000) "Three issues in consumer quality perception and acceptance of dairy products", International Dairy Journal, Vol. 10, pp. 575-584.

Hensher, D.A., Rose, J.M. and Greene, W.H. (2005). Applied Choice Analysis: a primer. Cambridge, U.K., Cambridge university press, 712p.

Hoefkens, C., Vandekinderen, I., De Meulenaer, B., Devlieghere, F., Baert, K., Sioen, I., De Henauw, S., Verbeke, W. and Van Camp, J. (2009). "A literature-based comparison of nutrient and contaminant contents between organic and conventional vegetables and potato". British Food Journal. In press.

IOM (2001). Dietary reference intakes for vitamin A, vitamin K, arsenic, boron, chromium, copper, iodine, iron, manganese, molybdenum, nickel, silicon, vanadium, and zinc. Institute of Medicine, Food and Nutrition Board, Washington, DC, National Academy Press, 800p.

Kahneman, D., and Tversky, A. (1979). "Prospect Theory: An Analysis of Decision under Risk”, Econometrica, Vol. XLVII, pp. 263-291.

Kahneman, D., Knetsch, J. L. and Thaler, R. H. (1990). "Experimental tests of the endowment effect and the Coase theorem". Journal of Political Economy, Vol. 98, pp. 1325-1348.

Kahneman, D., Knetsch, J. L. and Thaler, R. H. (1991). "Anomalies - the endowment effect, loss aversion and status-quo bias". Journal of Economic Perspectives, Vol. 5, pp. 193-206. 
Kontoleon, A. and Yabe, M. (2003), "Assessing the Impacts of Alternative 'Opt-out' Formats in Choice Experiment Studies: Consumer Preferences for Genetically Modified Content and Production Information in Food", Journal of Agricultural Policy Research, Vol. 5, pp. 1-43.

Lancaster , K.J. (1966). “A new approach to consumer theory". Journal of Political Economy, Vol. 74, pp. $132-157$.

Liljenstolpe, C. (2005). Valuing animal welfare with choice experiments: An application to Swedish pig production. Paper prepared for presentation at the 99th seminar of the EAAE (European Association of Agricultural Economists), KVL Copenhagen, Denmark, August 24$27,2005$.

Magnusson, M. K., Arvola, A., Hursti, U. K. K., Aberg, L., and Sjoden, P. O. (2003) "Choice of organic foods is related to perceived consequences for human health and to environmentally friendly behaviour", Appetite, Vol. 40 No. 2, pp. 109-17.

Marette, S., Crespi J. M. and Schiavina. A. (1999) "The role of common labelling in a context of asymmetric information”, European Review of Agricultural Economics, Vol. 26, pp. 167178.

McFadden, D. (1974). Conditional logit analysis of qualitative choice behavior. In P. Zarembka (Ed.), Frontiers of econometrics (pp. 105-142). New York: Academic Press.

Mondelaers, K., Aertsens, J. and Van Huylenbroeck, G. (2009). A meta-analysis of the differences in environmental impacts between organic and conventional farming. Submitted to British Food Journal.

O'Donovan, P. and McCarthy, M. (2002). "Irish consumer preference for organic meat". British Food Journal. Vol. 104 No. 3/4/5, pp. 353-370.

Platteau, J., Bas, L., Bernaerts, E., Campens, V., Carels, K., Demuynck, E., Hens, M., Overloop, S., Samborski, V., Smets, D., Van Gijseghem, D., Vriesacker, M., Wustenberghs, H. (2006). Landbouwbeleidsrapport 2005 (LARA). Brussel, Administratie, Departement Landbouw en Visserij, Afdeling Monitoring en Studie, D/2006/3241/155, pp. 240.

Roberts, J. A., (1996). Green consumers in the 1990s: Profile and implications for advertising. Journal of Business Research, Vol. 36, pp. 217-231.

Saher, M., Lindeman, M., and Hursti, U. K. K. (2006) "Attitudes towards genetically modified and organic foods", Appetite, Vol. 46 No. 3, pp. 324-31.

Train. K. (2003). Discrete Choice Methods with Simulation. Cambridge University Press, Cambridge, UK.

Tregear, A., Dent, J. B., and McGregor, M. J. (1994). The demand for organically grown produce. British Food Journal, Vol. 96, pp. 21-25.

Verbeke, W. (2005). Agriculture and the food industry in the information age. European Review of Agricultural Economics, Vol. 32 No. 3, pp. 347-368. 
Verbeke, W., Van de Velde, L., Mondelaers, K., Kuhne, B., and Van Huylenbroeck, G. (2008) "Consumer attitude and behaviour towards tomatoes after 10 years of Flandria quality labelling", International Journal of Food Science and Technology, Vol. 43 No. 9, pp. 1593601.

Verhoef, P.C. (2005). "Explaining purchases of organic meat by Dutch consumers", European Review of Agricultural Economics, Vol. 32, pp. 245-67.

Wandel, M., and Bugge, A. (1997). Environmental concern in consumer evaluation of food quality. Food Quality and Preference, Vol. 8, 19-26.

Willer, H. and Youssefi, M. (2007). The World of Organic Agriculture - Statistics and Emerging Trends 2007. International Federation of Organic Agriculture Movements IFOAM, Bonn, Germany and Research Institute of Organic Agriculture FiBL, Ackerstrasse, Switzerland.

Wong, V., Turner, W., Stoneman, P., (1996). Marketing Strategies and Market Prospects for Environmentally-Friendly Consumer Products. British Journal of Management, Vol. 7, pp. 263-281. 